\title{
S100A4 mediates endometrial cancer invasion and is a target of TGF- $\beta 1$ signaling
}

\author{
Ran Xie ${ }^{1}$, Matthew P Schlumbrecht ${ }^{2}$, Gregory L Shipley ${ }^{3}$, Susu Xie ${ }^{1}$, Roland L Bassett $\mathrm{Jr}^{4}$ and Russell R Broaddus ${ }^{1}$
}

The molecular mechanisms of endometrial cancer invasion are poorly understood. S100A4, also known as FSP1 (fibroblast-specific protein 1), has long been known to be a molecular marker of fibrosis in a variety of different fibrotic diseases of the lungs, liver, kidney, and heart. We demonstrate here that increased expression of S100A4 is associated with advanced stage endometrial cancer and decreased recurrence free survival. To verify the essential role of S100A4 in invasiveness of endometrial cancer, S100A4 expression was downregulated by RNAi in HEC-1A cells, which resulted in undetectable S100A4 protein and significantly decreased migration and invasion. Owing to the established connection between TGF- $\beta 1$ and S100A4 induction in experimental models of kidney and liver fibrosis, we next examined whether TGF- $\beta 1$ could also regulate S100A4 in endometrial cancer cells. TGF- $\beta 1$ stimulated endometrial cancer cell migration and invasion with a concomitant increase in S100A4 protein. Induction of S100A4 was associated with the activation of Smads. TGF- $\beta 1$-mediated endometrial cancer cell motility was inhibited by S100A4 siRNA. In aggregate, these results suggest that S100A4 is a critical mediator of invasion in endometrial cancer and is upregulated by the TGF- $\beta 1$ signaling pathway. These results also suggest that endometrial cancer cell invasion and fibrosis share common molecular mechanisms.

Laboratory Investigation (2009) 89, 937-947; doi:10.1038/labinvest.2009.52; published online 8 June 2009

KEYWORDS: endometrial cancer; S100A family genes; S100A4; cancer invasion; epithelial-to-mesenchymal transition

S100A4, also known as FSP1 (fibroblast-specific protein 1), is well known to be overexpressed in fibrotic diseases of the lung, kidney, liver, and heart. ${ }^{1-5}$ In normal adult tissues, its expression is confined to fibroblasts and other cell types of mesenchymal origin. Previously, we identified high expression of S100A4 to be associated with adverse clinical-pathological factors for endometrial cancer, including higher endometrioid grade, non-endometrioid histology, and advanced stage. ${ }^{6}$ In normal endometrium and lower grade endometrioid carcinomas, S100A4 protein is only weakly expressed in stromal cells, with no epithelial expression. However, in the higher grade endometrioid carcinomas and the non-endometrioid carcinomas, S100A4 protein is expressed in tumor epithelial cells. ${ }^{6}$ Owing to this drastic change in the pattern of S100A4 expression, we have speculated that epithelial-to-mesenchymal transition (EMT) is a critical event in the development of an invasive endometrial cancer.
S100A4 belongs to the $S 100$ gene family, a multi-gene family of $\mathrm{Ca}^{2+}$-binding proteins of the EF-hand type. These genes are involved in a variety of cellular processes, such as immune response, differentiation, cytoskeleton dynamics, and cell growth. ${ }^{7,8}$ To date, 20 members of the $S 100$ family have been identified in humans. ${ }^{8}$ The majority of the $S 100$ genes are clustered in a region of chromosome 1q21, which is frequently rearranged in a number of malignancies, including endometrial cancer. ${ }^{9}$ Members of the $S 100$ gene family are highly conserved, but individual S100 proteins show cell- and tissue-specific expression patterns. ${ }^{7}$ Interestingly, several S100 proteins, such as S100A2, S100A4, S100A6, S100A7, S100A9, S100A10, and S100A11 are specifically upregulated in aggressive, advanced, metastatic tumors relative to non-invasive, non-metastatic tumors. ${ }^{6,10-18}$ The preferential expression patterns of these proteins in more invasive and metastatic tumors has led them to become regarded as potential prognostic markers. ${ }^{8}$ In most cases the mechanisms

\footnotetext{
${ }^{1}$ Department of Pathology, University of Texas M.D. Anderson Cancer Center, Houston, TX, USA; ${ }^{2}$ Department of Gynecologic Oncology, University of Texas M.D. Anderson Cancer Center, Houston, TX, USA; ${ }^{3}$ Department of Integrative Biology and Pharmacology, University of Texas Health Science Center-Houston, Houston, TX, USA and ${ }^{4}$ Department of Biostatistics, University of Texas M.D. Anderson Cancer Center, Houston, TX, USA

Correspondence: Dr RR Broaddus, MD, PhD, Department of Pathology, Unit 85, University of Texas M.D. Anderson Cancer Center, 1515 Holcombe Blvd, Houston, TX 77030-4095, USA.

E-mail: rbroaddus@mdanderson.org

Received 10 April 2009; revised 4 May 2009; accepted 6 May 2009
} 
of action of S100 proteins and the functional implication of their altered expression in cancers are still unknown. Furthermore, the mechanisms regulating expression of the $S 100$ genes in cancers are largely unknown. In this study, we examined the transcriptional expression of S100A2, S100A4, S100A6, S100A7, S100A9, S100A10, and S100A11 in a large set of human endometrial tumors and normal endometrial tissues and further correlated their expression with welldocumented clinicopathologic parameters of aggressiveness and poor prognosis of endometrial cancer. Only S100A4 expression was significantly associated with all of these aggressive features, so it was chosen for more detailed mechanistic studies that are summarized here.

\section{MATERIALS AND METHODS Human Normal Endometrial Tissues, Tumor Samples, and Cell Lines}

This study was approved by the University of Texas M.D. Anderson Cancer Center Institutional Review Board (LAB01718). Fresh frozen endometrial carcinoma specimens $(n=108)$ and normal endometrial tissues $(n=19)$ were obtained as residual tissues from hysterectomy surgical specimens submitted to the Department of Pathology, M.D. Anderson Cancer Center. The frozen tumor tissues were acquired from the luminal portion of the endometrial cancer so as not to interfere with pathological staging of myometrial invasion. A gynecological pathologist (RRB) microscopically reviewed H\&E-stained slides to confirm surgical stage, tumor grade, and histotype based on the criteria established by the International Federation of Gynecology and Obstetrics. ${ }^{19}$ Tumor recurrence and recurrence free and overall survival were identified by review of clinical documentation in the electronic medical record. A diagnosis of recurrent disease was made by identification of a new lesion on clinical exam or visualization of a new mass on radiographic imaging. Recurrence free survival was defined as the interval between the date of primary surgical treatment and the date of tumor recurrence, and overall survival as the time from primary surgery until date of death or date of last recorded follow-up.

The human endometrial adenocarcinoma cell lines HEC$1 \mathrm{~A}$ and KLE were obtained from the American Type Culture Collection (ATCC, Rockville, MD, USA). These endometrial cancer cell lines were chosen because we have shown earlier that the HEC-1A cells have high endogenous levels of S100A4 and are highly invasive. The KLE cells, on the other hand, have low endogenous levels of S100A4 and are minimally invasive. $^{6}$ All endometrial cancer cells were cultured in McCoy's 5a medium with $10 \%$ FBS.

\section{RNA Isolation}

RNA was isolated from frozen tissue samples using TRIzol (Invitrogen, Carlsbad, CA, USA) followed by an additional purification step using the RNeasy kit (Qiagen, Valencia, CA, USA) following the manufacturer's recommendations.

\section{Quantitative Real-Time RT-PCR}

Quantitative real-time RT-PCR was performed using the 7700 Sequence Detector (Applied Biosystems, Foster City, CA, USA) as described earlier. ${ }^{20}$ Probe-based real-time quantitative assays for S100A2, S100A4, S100A6, S100A7, S100A9, S100A10, S100A11, and 18S rRNA were developed using Primer Express software (Applied Biosystems) based on sequences from Genbank. The assays were developed and all real-time qRT-PCR reactions were run in the Quantitative Genomics Core Laboratory (UT-Houston Medical School, Houston, TX, USA). The primer and probe sequences, accession number, and pertinent information for each assay are listed in Table 1. Each qRT-PCR experiment was performed in duplicate using assay-specific sDNAs (synthetic amplicon oligonucleotides, Biosource, Camarillo, CA, USA) serially diluted in 10-fold decrements to obtain a standard curve covering a 5-log range in template concentration. A linear relationship between the threshold cycle $(\mathrm{Ct})$ and the log of the starting sDNA copy number was always established (correlation coefficient $>0.99$ ) and used to construct a standard curve. The copy number for each transcript assayed was interpolated from the standard curve by the ABI SDS software. The final transcript values were normalized to those determined for $18 \mathrm{~S}$ rRNA.

\section{Western Blot Analysis}

Endometrial cancer cell line lysates were prepared in ice-cold lysis buffer $(50 \mathrm{mmol} / \mathrm{l}$ Tris (pH 8.0), $100 \mathrm{mmol} / \mathrm{l} \mathrm{NaCl}, 0.1 \%$ SDS, $1 \%$ NP-40, $0.5 \mathrm{mM}$ EDTA) containing the protease inhibitor cocktail Complete (Roche, Mannheim, Germany). Proteins $(20 \mu \mathrm{g})$ were boiled for $5 \mathrm{~min}$ and then subjected to 15 or $10 \%$ SDS-PAGE gels. Samples were then blotted onto a nitrocellulose membrane (Bio-Rad, Hercules, CA, USA), blocked for $1 \mathrm{~h}$ in $5 \%$ skim milk in PBS, and probed with anti-S100A4 antibody (1:200 dilution, DAKO, Carpinteria, CA, USA); anti- $\beta$-actin antibody (1:100 000 dilution, Sigma Chemicals, St Louis, MO, USA), anti- $\alpha$-tubulin antibody (1:1000 dilution, Santa Cruz Biotechnology); anti-phosphoSmad2 (Ser465/467) (1:1000 dilution, Cell Signaling Technology, Danvers, MA, USA); anti-Smad2 (1:1000 dilution, BD Bioscience, Bedford, MA); anti-AKT (1:1000 dilution, Cell Signaling Technology); anti-phospho-AKT (Ser 473) (1:1000 dilution, Cell Signaling Technology); anti-Erk1/2, and anti-phospho (Thr-202/Tyr-204)-Erk1/2 (1:1000 dilution, Cell Signaling Technology), followed by anti-rabbit or anti-mouse IgG secondary antibodies (Amersham Bioscience, Piscataway, NJ). The Enhanced Chemiluminescence kit (Amersham Bioscience) was used for detection.

\section{RNA Interference Experiments}

S100A4 siRNA pool was commercially purchased from Dharmacon (Lafayette, CO, USA). Negative non-targeting control siRNA from Dharmacon was also used. By using a DharmaFECT transfection kit (Lafayette, CO, USA), cells were transfected with either non-targeting control siRNA 
Table 1 Probes and primers for real-time quantitative RT-PCR assays

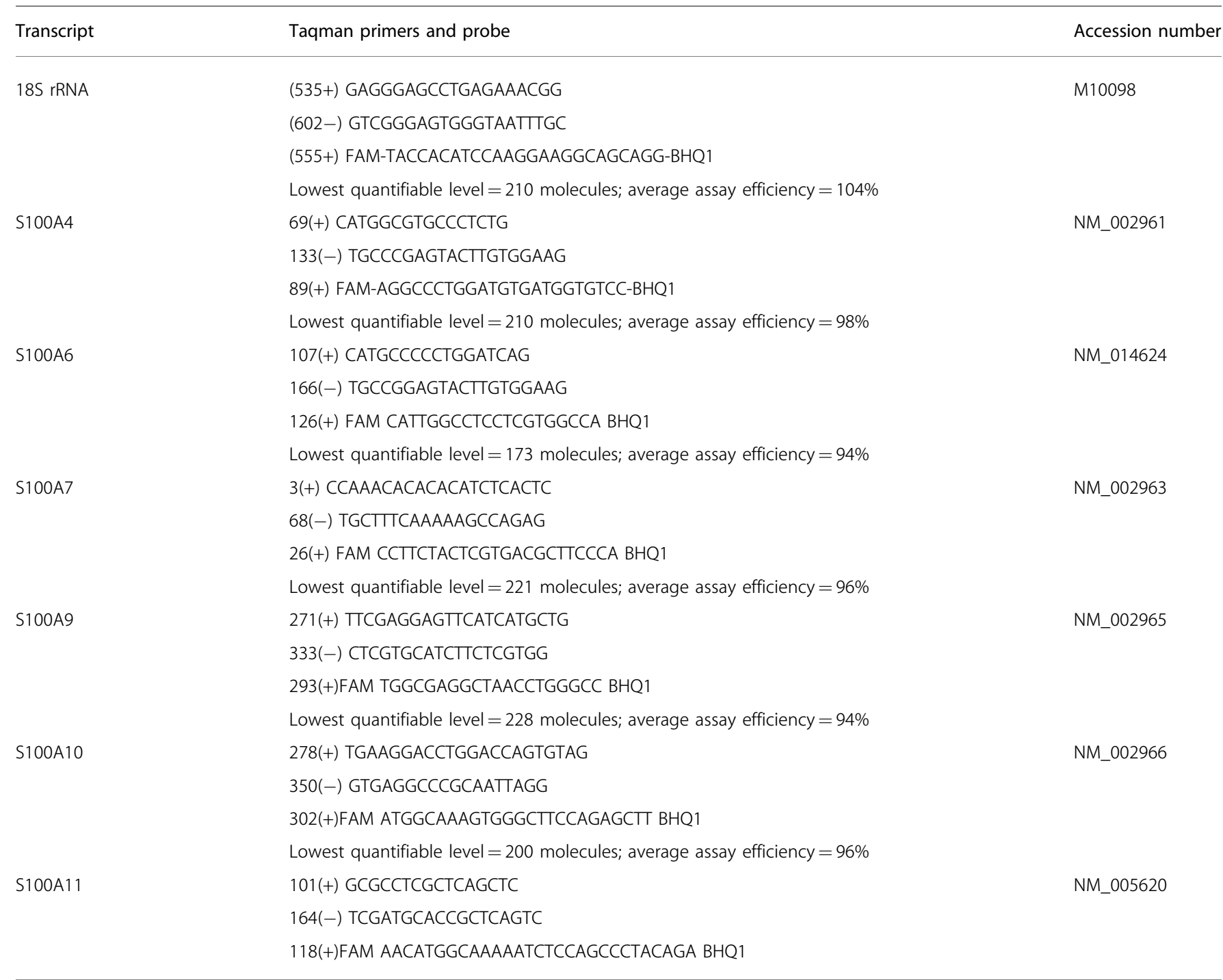

(100 nM) or S100A4 siRNA (100 nM). S100A4 short hairpin RNA (shRNA) construct was commercially purchased from Open Biosystems (Huntsville, AL). Transfections were performed using the Arrest-In transfection reagent from Open Biosystems, and stable transfectants were created with the addition of $1 \mu \mathrm{g} / \mathrm{ml}$ puromycin (Sigma-Aldrich, St Louis, MO, USA) to the culture medium. A non-silencing shRNA construct (Open Biosystems) was used as a negative control.

The effectiveness of gene silencing was determined by performing qRT-PCR and western blot analysis.

\section{In Vitro Cell Proliferation}

HEC-1A or KLE endometrial cancer cells were seeded in triplicate in tissue culture dishes and cultured in complete medium. Medium was replaced every second day. Every $24 \mathrm{~h}$ for 5 days, the growth medium was collected, cells were trypsinized and added to the growth media, centrifuged at 1000 r.p.m. for $5 \mathrm{~min}$, re-suspended in a known volume of media, and counted in trypan blue with a hemacytometer to determine the total number of viable cells present.

\section{Migration and Invasion Assays}

Migration and invasion assays for HEC-1A cells with manipulated S100A4 expression were performed as described by Albini et al. ${ }^{21,22}$ In brief, HEC-1A cell migration was quantified using a modified two-chamber migration assay $(8 \mu \mathrm{m}$ membrane pore size, BD Bioscience) or a modified twochamber invasion assay (membrane coated with a layer of Matrigel extracellular matrix proteins, BD Bioscience) according to the manufacturer's instructions. The bottom chamber was filled with $750 \mu \mathrm{l}$ of NIH/3T3 conditioned media, and the insert was placed into the conditioned media. An aliquot containing $2 \times 10^{5}$ cells suspended in serum-free culture media was seeded in the top insert. NIH/3T3 conditioned medium served as a chemoattractant in the lower chamber. The HEC-1A cells were allowed to migrate/invade 
for $22 \mathrm{~h}$ at $37^{\circ} \mathrm{C}$. Cells in the upper chamber were carefully removed using cotton buds, and cells attaching to the lower surface of the membrane were fixed and stained with the HEMA 3 Stain set (Fisher Diagnostics, Middletown, VA, USA). Quantification was performed by counting the stained cells under light microscopy.

\section{Wound-Healing Assays}

Wound-healing assays were performed to confirm the Boyden chamber migration data. HEC-1A cells with manipulated S100A4 expression were grown in McCoy's 5A with 10\% FBS in six-well cell culture plates until they reached $100 \%$ confluence. A small linear scratch was introduced in the middle of the confluent cells using a $10 \mu \mathrm{l}$ pipette tip and a photomicrograph was taken for the 0 time point. All scratches were carefully performed to assure equal width of the scratch made and also as to the location of the scratch so that all photomicrographs after time 0 were taken at the same point of the scratch. Cells were then returned to the incubator for continued growth. Cells were only removed from the incubator at the designated time points ( 24 and $48 \mathrm{~h}$ ) when photomicrographs were taken to monitor the cell migration progress.

\section{TGF- $\beta 1$ Treatments In Vitro}

The HEC-1A cells or KLE cells were seeded at low density $\left(10^{5}\right.$ cells/well) on six-well plates (day 0$)$. The cells were allowed to attach for $24 \mathrm{~h}$, after which time they were rinsed twice with PBS, followed by the addition of serum-free medium containing either $2.5 \mathrm{ng} / \mathrm{ml}$ of human TGF- $\beta 1$ ( $\mathrm{R} \&$ D systems, Minneapolis, MN, USA) or an equal volume of TGF- $\beta 1$ vehicle $(4 \mathrm{mM} \mathrm{HCl}$ with $1 \mathrm{mg} / \mathrm{ml}$ bovine serum albumin) and incubated for a period of time as indicated. The medium, with growth factor or vehicle, was replaced daily. The cells were photographed and evaluated for morphological change every $48 \mathrm{~h}$. All cells were assayed in triplicate for both control and TGF- $\beta 1$-treated conditions.

\section{Statistical Analysis}

Statistical differences were calculated using the MannWhitney $U$-test and ANOVA. The Tukey HSD procedure was used to adjust for multiple comparisons. Correlation between two variables was evaluated by the Spearman rank correlation test. The Kaplan-Meier method was applied to generate survival estimates, and Cox proportional hazards regression models were used to model the association between survival and covariates of interest. For all statistical analyses, differences were considered significant if $P<0.05$.

\section{RESULTS}

\section{Overexpression of S100A2, S100A4, S100A7, and S100A9 in Endometrial Cancer}

Using real-time quantitative PCR (qRT-PCR), we quantified the transcript levels of S100A2, S100A4, S100A6, S100A7, S100A9, S100A10, and S100A11 in a series of endometrial cancers (endometrioid tumors, $n=71$; non-endometrioid tumors, $n=21)$ and normal endometrial tissues $(n=17)$. These $S 100$ genes were chosen because they had been shown earlier in the literature to be overexpressed in different cancer types. S100A2, S100A4, S100A7, and S100A9 all showed elevated levels of mRNA in endometrial cancer compared with benign endometrium (Figure 1). For each of these $S 100$ genes, mRNA expression tended to be highest in the higher grade tumors. However, there were distinct differences in expression among the four genes. S100A4 was overexpressed only in grade 3 endometrioid carcinoma and the non-endometrioid tumors uterine papillary serous carcinoma (UPSC) and malignant mixed Mullerian tumor (MMMT); these histotypes are most often associated with deep myometrial invasion and metastasis. S100A7, on the other hand, was significantly elevated in grades 2 and 3 endometrioid carcinoma, but was not increased in the non-endometrioid tumors. Overall, S100A7 expression was very low compared with the other S100s examined, so the significance of its overexpression in higher grade endometrioid tumors is uncertain. S100A2 expression was significantly increased in all grades of endometrioid tumors as well as in the non-endometrioid tumors. Expression in UPSC, although elevated overall compared to benign endometrium, was highly variable. S100A9 was significantly increased in grades 2 and 3 endometrioid tumors as well as in UPSC and MMMT. Mean expression values for S100A6, S100A10, and S100A11 were not significantly different from normal endometrium for any of the tumor histotypes investigated (data not shown).

\section{Expression of S100 Genes in Relation to Clinicopathologic Indicators of Endometrial Cancer Invasiveness}

We next compared the expression levels of the four $S 100$ genes that were elevated in endometrial cancers compared with benign endometrium in relation to well-established clinicopathologic indicators of endometrial cancer invasiveness, including myometrial invasion greater than $50 \%$ uterine wall thickness, lymphatic/vascular invasion, and extra-uterine disease (Table 2). Only overexpression of S100A4 was significantly associated with all three of these indicators of endometrial cancer invasiveness. Importantly, S100A4 was also significantly overexpressed in the histotypes of endometrial cancer (grade 3 endometrioid carcinoma, UPSC, and MMMT) most often associated with deep myometrial invasion and metastasis (Figure 1). Rates of recurrence, overall survival, and progression-free survival were analyzed in relation to S100A4 expression. S100A4 was significantly higher in the 27 primary tumors from patients who later had recurrence (15.51 vs 8.06, $P=0.009$ ). S100A4 expression did not correlate with overall survival (HR 1.87 [95\% CI $0.64-$ 5.47]; $P=0.25$ ). However, there was significantly decreased recurrence-free survival with increasing S100A4 expression (HR 4.39 [95\% CI 1.48-13.09]; $P=0.001$ ). Therefore, based on the results described above, we chose to study S100A4 in 
a

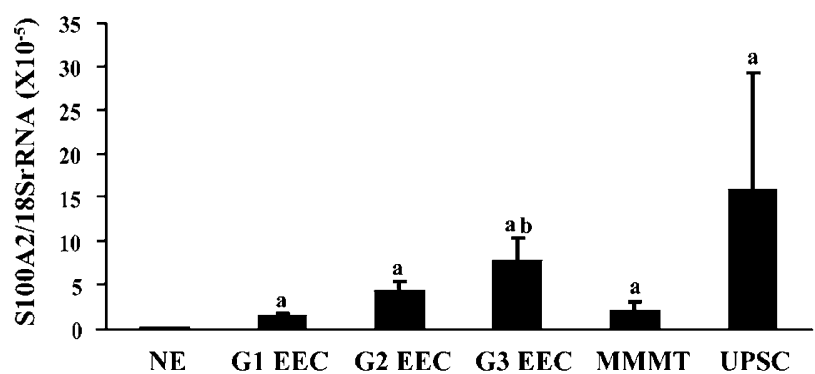

c

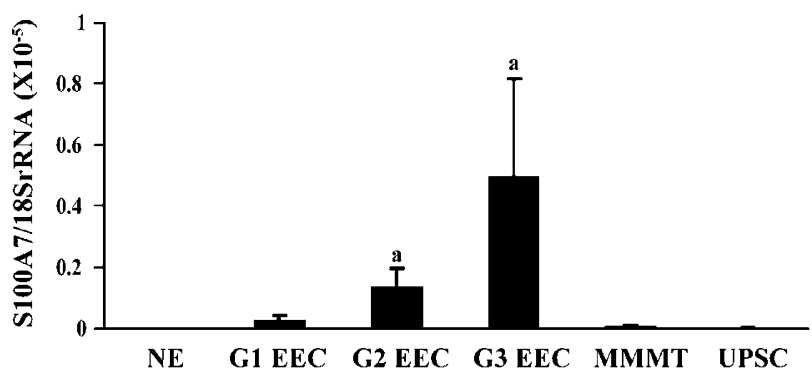

b

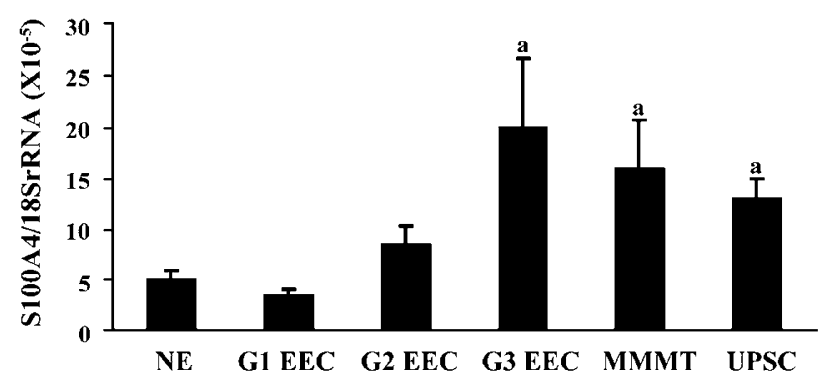

d

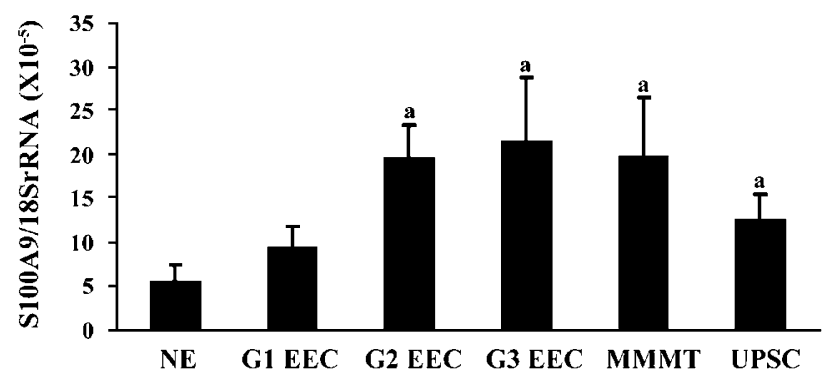

Figure 1 qRT-PCR analysis of S100 family members in benign endometrium and endometrial cancer. S100A transcripts were measured by qRT-PCR in normal endometrium (NE; $n=17$ ), grade 1 endometrioid adenocarcinoma (G1 EEC; $n=14$ ), grade 2 endometrioid adenocarcinoma (G2 EEC; $n=34$ ), grade 3 endometrioid adenocarcinoma (G3 EEC; $n=23$ ), malignant mixed Mullerian tumor (MMMT; $n=11$ ), and uterine papillary serous carcinoma (UPSC; $n=10$ ). Final transcript data were normalized to $18 \mathrm{~S}$ rRNA and are presented as the molecules of transcript/molecules of $18 \mathrm{~S}$ rRNA. Values shown are mean \pm s.e. (a) S100A2 was overexpressed in all subtypes of endometrial cancer compared with benign endometrium $(a, P<0.01)$. S100A2 levels in G3 EEC were significantly higher than those for G1 EEC (b, $P=0.007$ ). (b) S100A4 was significantly overexpressed in G3 EEC, MMMT, and UPSC compared with benign endometrium, G1 EEC and G2 EEC (a, $P<0.01)$. (c) S100A7 was overexpressed in G2 EEC and G3 EEC compared with NE (a, $P \ldots 0.01)$, but not in the nonendometrioid tumors UPSC and MMMT. (d) S100A9 was significantly increased in G2 EEC, G3 EEC, MMMT, and UPSC compared with NE (a, $P$...0.05).

Table 2 qRT-PCR expression of S100 gene family members in association with clinicopathological indicators of endometrial cancer invasiveness ${ }^{\mathrm{a}}$

\begin{tabular}{|c|c|c|c|c|c|c|}
\hline & \multicolumn{2}{|c|}{ Deep myometrial invasion ${ }^{b}$} & \multicolumn{2}{|c|}{ Lymphatic/vascular space invasion } & \multicolumn{2}{|c|}{ Extra-uterine corpus metastasis } \\
\hline & Absent & Present & Absent & Present & Absent & Present \\
\hline S100A4 & $3.9 \pm 0.7$ & $14.9 \pm 4.7^{\star}$ & $5.1 \pm 1.1$ & $16.5 \pm 4.6^{*}$ & $7.0 \pm 1.4$ & $19.0 \pm 6.0^{*}$ \\
\hline $\mathrm{S} 100 \mathrm{~A} 2$ & $3.7 \pm 0.9$ & $6.1 \pm 2.4$ & $1.5 \pm 0.3$ & $7.0 \pm 2.2^{*}$ & $2.9 \pm 0.6$ & $8.4 \pm 3.0^{*}$ \\
\hline
\end{tabular}

\footnotetext{
${ }^{\mathrm{a}}$ Final transcript data were normalized to $18 \mathrm{~S}$ rRNA and presented as [(molecules of transcript/molecules of $18 \mathrm{~S}$ rRNA) $\times 10^{-5}$ ]. Values shown are mean \pm s.e.

${ }^{b}$ Deep myometrial invasion is defined as invasion greater than or equal to $50 \%$ myometrial wall thickness. ${ }^{\star} P<0.05$.
}

greater detail. It is important to note, however, that other S100 genes, especially S100A2, S100A7, and S100A9, may also play important roles in endometrial cancer.

\section{Effects of S100A4 Gene Knockdown on Cell Migration and Invasion and Cell Proliferation}

On the basis of important clinical associations of high S100A4 expression with depth of myometrial invasion, stage, and recurrence, we next wanted to test the hypothesis that overexpression of S100A4 is an actual contributor to the aggressive phenotype in endometrial cancer. To accomplish this, we manipulated the expression of S100A4 in endometrial cancer cell lines and determined its effects on cell migration and invasion. From our previous published studies, we have shown that HEC-1A and HEC-1B endometrial cancer cells have high endogenous S100A4 mRNA and protein levels and are highly invasive, whereas Ishikawa and KLE endometrial cancer cells have low levels of endogenous 

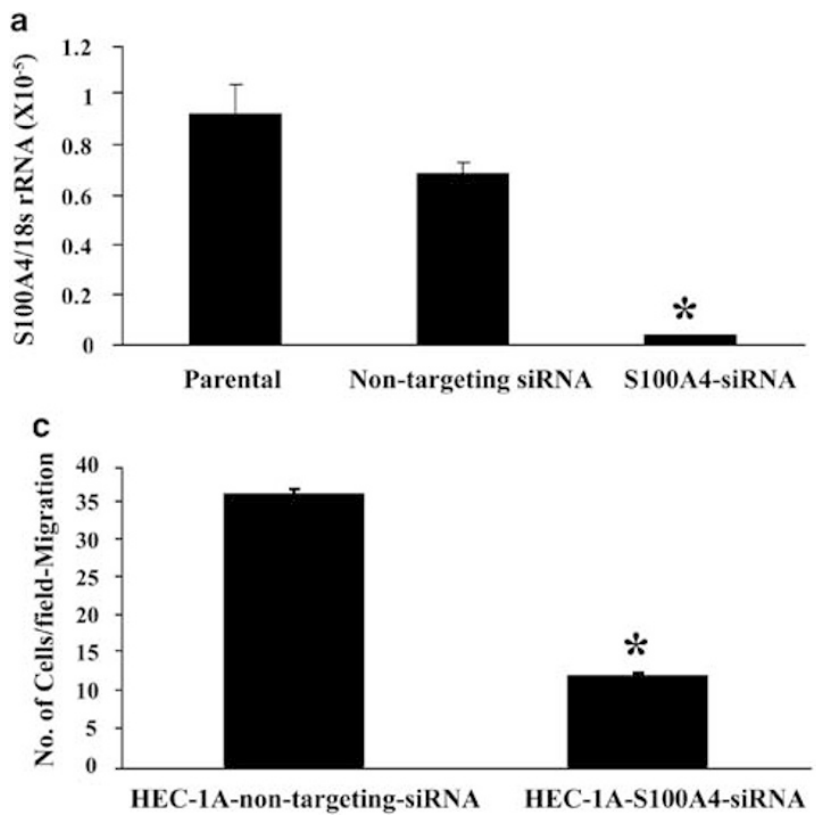

b
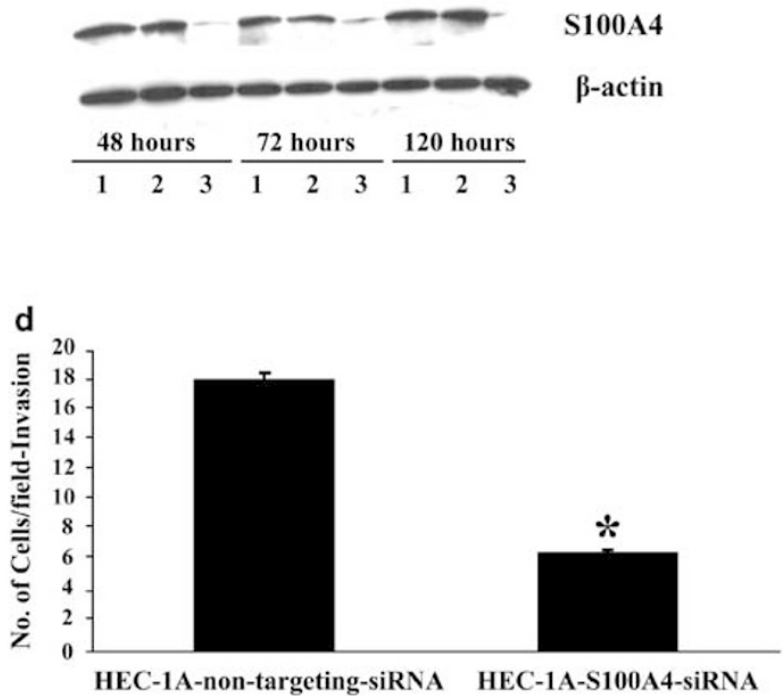

Figure 2 S100A4 gene knockdown by siRNA transfection in HEC-1A cells. (a) By qRT-PCR, S100A4 mRNA expression was significantly suppressed at $36 \mathrm{~h}$ post transfection of S100A4 siRNA into HEC-1A cells as compared with non-targeting siRNA transfected cells and parental cells. (b) By western blot analysis, S100A4 protein expression was decreased in HEC-1A cells at $48 \mathrm{~h}$ post transfection of S100A4 siRNA and remained at low levels at $120 \mathrm{~h}$ post transfection. Lane 1, HEC-1A parental cells; lane 2, non-targeting siRNA transfected HEC-1A cells; lane 3, S100A4 siRNA transfected HEC-1A cells. For qRT-PCR, data were normalized to $18 \mathrm{~S}$ rRNA and are presented as the molecules of transcript/molecules of $18 \mathrm{~S}$ rRNA. Values shown are mean \pm s.e. For western blot analysis, equal loading of protein was confirmed by stripping the blots and reprobing with $\beta$-actin antibody. (c and d) Knockdown of S100A4 protein in HEC-1A endometrial cancer cells resulted in decreased migration (c) and invasion (d). HEC-1A endometrial cancer cells were transfected with control non-targeting siRNA or S100A4 siRNA at $48 \mathrm{~h}$ post transfection. After microscopic examination, migratory and invasive potentials of the cells were quantified. The invasion and migration assays were performed in triplicate, and means were used in statistical analysis $\left({ }^{*} P<0.001\right)$.

S100A4 and are minimally invasive. ${ }^{6}$ Hence, we chose HEC$1 \mathrm{~A}$ endometrial cancer cells for the siRNA experiments. Transient transfection of S100A4 siRNA resulted in significant downregulation of both S100A4 mRNA and protein. At $36 \mathrm{~h}$ post transfection, the mRNA expression levels of S100A4 decreased to roughly $5 \%$ of the non-targeting siRNA control expression levels (Figure 2a). Similarly, S100A4 protein expression was reduced dramatically at $48 \mathrm{~h}$ post transfection and the reduction persisted at 5 days (Figure $2 \mathrm{~b}$ ). In comparison with non-targeting siRNA transfected cells, cells at $48 \mathrm{~h}$ post transfection of S100A4 siRNA exhibited a significant reduction in cell migration and invasion (Figure $2 \mathrm{c}$ and $d$ ). Thus, the results of these experiments suggest that S100A4 is a critical mediator of endometrial cancer cell migration and invasion.

For long-term stable suppressed expression of S100A4 in HEC-1A cells, stable S100A4 knockdown clones were generated by transfection of S100A4-specific shRNA into HEC-1A cells, and stable transfectants were selected and expanded. Two S100A4 knockdown clones were produced, with undetectable S100A4 protein compared to control empty vector clones (Figure 3a). Stable S100A4 gene knockdown caused significant decreases in cell migration in a wound assay (Figure $3 \mathrm{~b}$ ) and in migration and invasion in the two-chamber assay (data not shown), similar to what was observed with transient knockdown. For the endometrial cancer cells, knockdown of S100A4 expression had no significant effect on cell proliferation in vitro (Figure 3c).

In aggregate, results from our clinical-pathological associations and the more functional studies from the HEC-1A endometrial cancer cells provide strong evidence that S100A4 is an important molecular mediator of endometrial cancer invasion.

\section{TGF- $\beta 1$ Signaling Upregulates S100A4 Expression}

Activation of TGF- $\beta$ and S100A4 have been shown to be important in models of kidney and liver fibrosis. ${ }^{1-3}$ However, S100A4 has not been linked earlier to TGF- $\beta 1$ in any cancer system. Therefore, we were interested in determining whether TGF- $\beta 1$ induces S100A4 in the human endometrial cancer cell line HEC-1A. We published earlier that for this cell line, the S100A4 gene was not methylated, which corresponded to high basal levels of S100A4 protein expression. ${ }^{6}$ S100A4 mRNA and protein were upregulated $96 \mathrm{~h}$ after TGF- $\beta 1$ treatment (Figure $4 \mathrm{a}$ and $\mathrm{b}$ ). This late induction of S100A4 is consistent with other reports that S100A4 was induced by prolonged stimulation of TGF- $\beta 1$ in cultured intrahepatic biliary epithelial cells or renal epithelial cells. ${ }^{1-3}$ We have demonstrated earlier that minimally invasive KLE endometrial cancer cells have low endogenous S100A4 
a

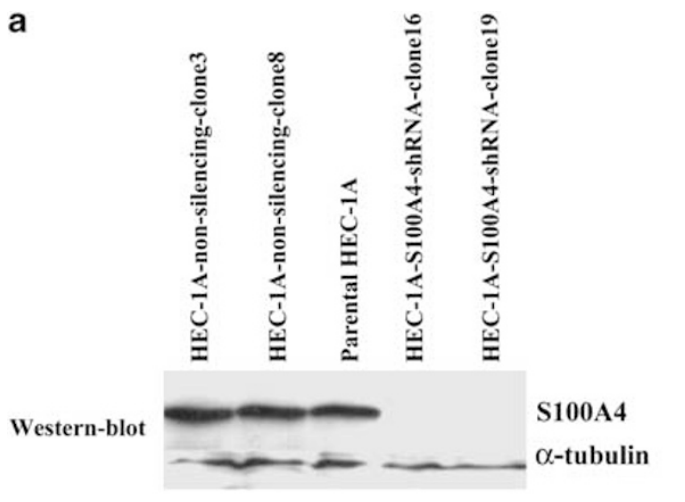

b

HEC-1A-non-silencing-c3
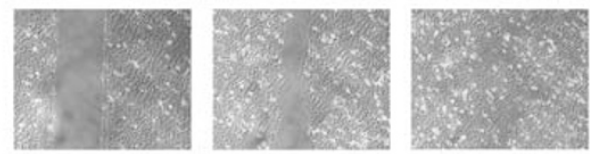

HEC-1A-non-silencing-c8
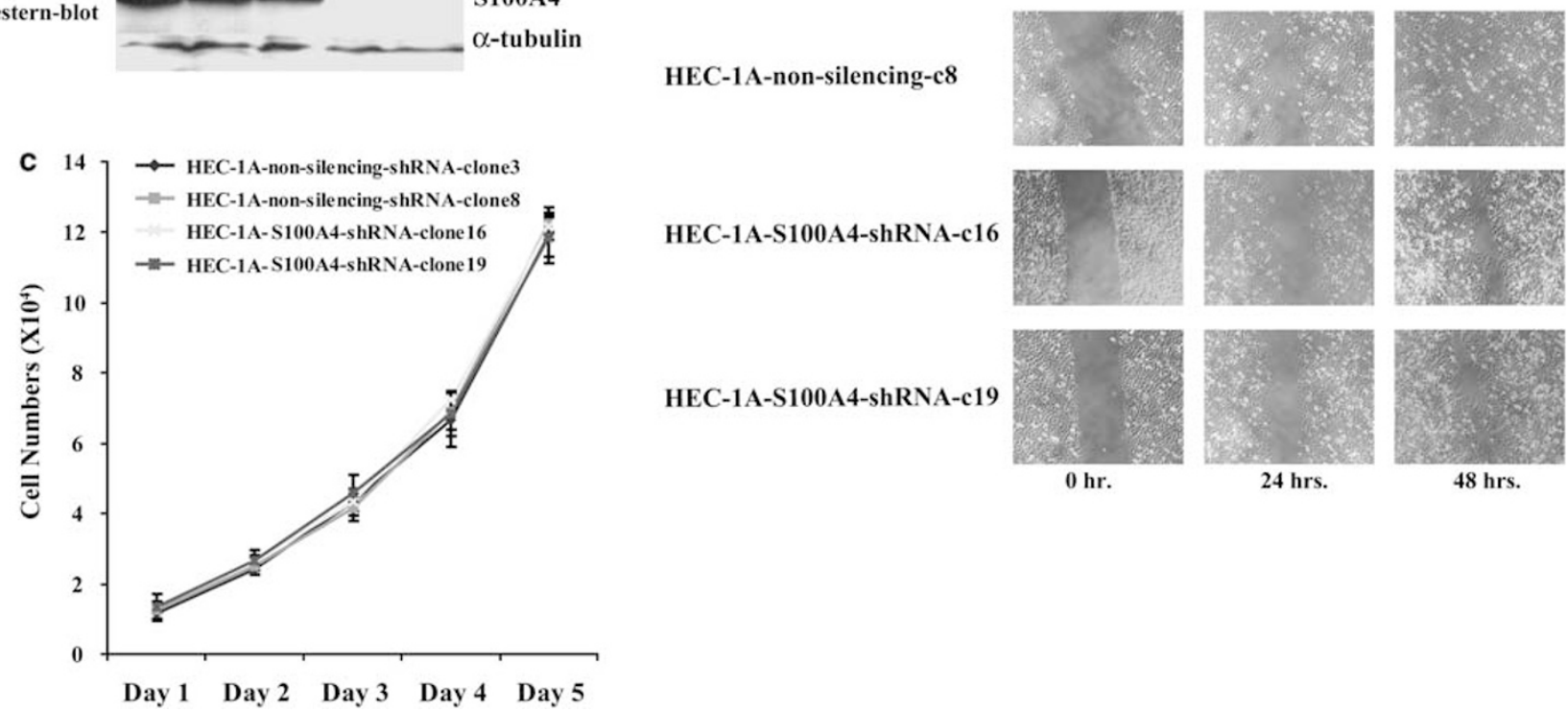
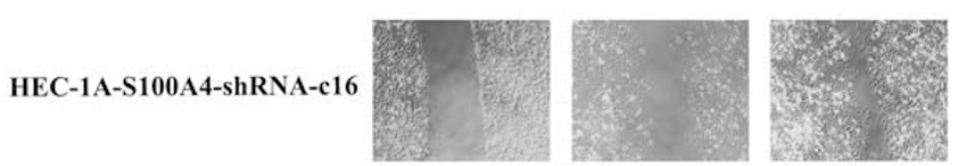

HEC-1A-S100A4-shRNA-c19
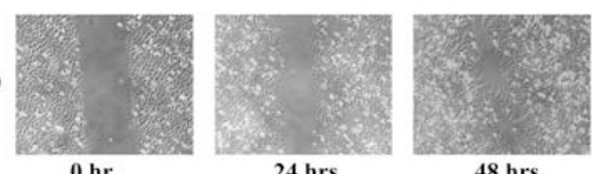

48 hrs.

Figure 3 Endometrial cancer cell migration and proliferation after S100A4 gene knockdown by shRNA transfection. (a) By western blot analysis, S100A4 protein expression was undetectable in two HEC-1A clones (c16 and c19) stably transfected with shRNA for S100A4 as compared with empty vector controls (c3 and $(8)$ and parental cells. Equal loading of protein was confirmed by stripping the blots and reprobing with $\alpha$-tubulin. (b) Wound-healing assay with S100A4 shRNA stable clones (HEC-1A-S100A4shRNA c16 \& HEC-1A-S100A4shRNA C19) and empty vector clones (HEC-1A-non-silencing shRNA c3 \& HEC-1Anon-silencing shRNA c8). A scratch was introduced in the middle of confluently grown cells. Photomicrographs were taken at designated time points to assess the ability of different cell types to heal the wound. (c) Knockdown of S100A4 had no effect on cell proliferation in vitro. Cell proliferation of S100A4 shRNA stable clones (HEC-1A-S100A4shRNA clone16 \& HEC-1A-S100A4shRNA clone19) and empty vector clones (HEC-1A-non-silencing shRNA clone 3 \& HEC-1A-non-silencing shRNA clone 8) was assessed by direct cell counting. Cells were seeded at a density of 10000 cells in a 12-well plate and counted every day for 5 days. Values are expressed as mean \pm s.e. of triplicate determinations.

transcript and protein because of hypermethylation of the S100A4 gene. ${ }^{6}$ TGF- $\beta 1$ does not induce S100A4 message in the KLE cells (Figure 4c), suggesting that epigenetic modifications, such as S100A4 gene methylation, may play an important role in determining responsiveness to TGF- $\beta 1$.

\section{S100A4 is Required for TGF- $\beta 1$ Effects on Cell Migration and Invasion}

In contrast to the growth inhibitory effects of TGF- $\beta 1$ on the early stages of carcinogenesis, TGF- $\beta 1$ can also act as a promoter of tumor cell invasion and metastasis in the later stages of tumorigenesis. ${ }^{23}$ We first examined the effects of TGF- $\beta 1$ on cell growth in HEC-1A cells. The growth of HEC$1 \mathrm{~A}$ cells was inhibited $48 \mathrm{~h}$ after TGF- $\beta 1$ stimulation (data not shown). However, HEC-1A cells pretreated with TGF- $\beta 1$ for 5 days exhibited increased migratory capability and invasiveness (Figure $5 \mathrm{a}$ and $\mathrm{b}$ ), concomitant with an increase in
S100A4 expression. We next wanted to determine whether S100A4 was necessary for the invasion and migration induced by TGF- $\beta 1$. In HEC-1A cells transfected with S100A4 siRNA, TGF- $\beta 1$ could not stimulate significant migration and invasion (Figure $5 \mathrm{c}$ and d). Consistent with our previous results (Figure 2), the S100A4 siRNA also significantly decreased the basal capability of these cells to migrate and invade (Figure $5 \mathrm{c}$ and $\mathrm{d}$ ). On the basis of these data, S100A4 expression is required for TGF- $\beta 1$ to exert its pro-migratory and pro-invasive effects on endometrial cancer cells. Therefore, S100A4 is a critical effector of endometrial cancer cell invasiveness.

Interestingly, we also found that the addition of TGF- $\beta 1$ to HEC-1A cells elicited morphological changes, as treated cells showed a somewhat elongated, spindle-like, fibroblast appearance compared with controls, which is indicative of EMT. EMT is classically associated with stimulation of cell 


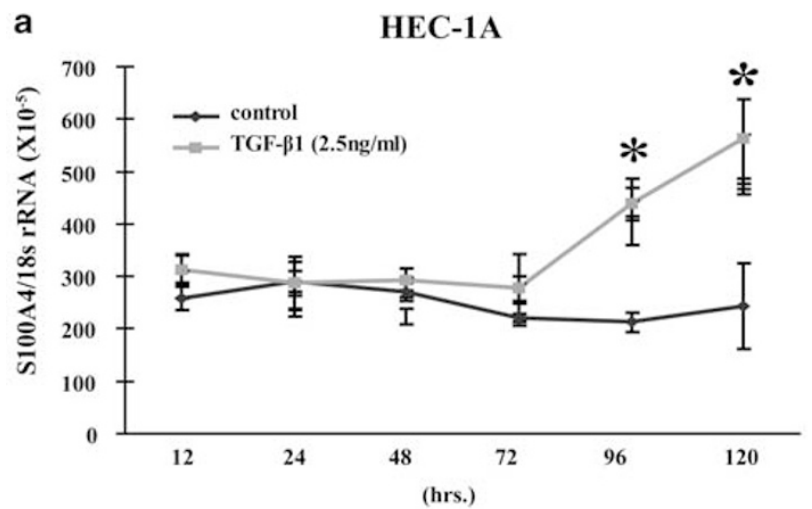

b
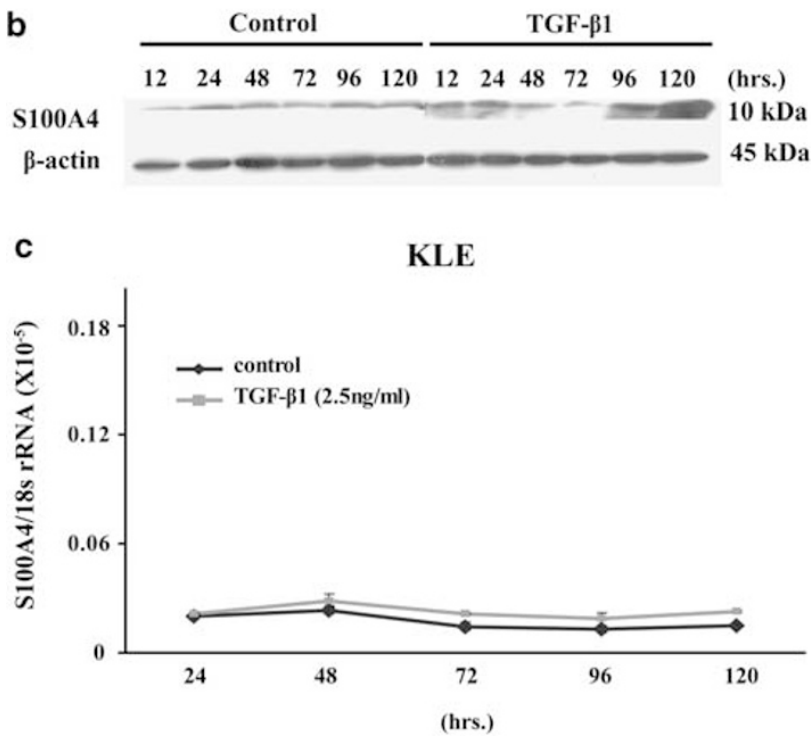

Figure 4 Upregulation of S100A4 expression after TGF- $\beta 1$ treatment. Cells were treated with TGF- $\beta 1(2.5 \mathrm{ng} / \mathrm{ml})$ or vehicle $(4 \mathrm{mM} \mathrm{HCl}$ with $1 \mathrm{mg} / \mathrm{ml}$ bovine serum albumin) in the absence of serum for the designated time intervals. (a) S100A4 mRNA level was induced $72 \mathrm{~h}$ after TGF- $\beta 1$ treatment and remained elevated at $120 \mathrm{~h}$ post treatment ( $\mathrm{qRT}-\mathrm{PCR} ;{ }^{*} P<0.05$ ).

(b) In HEC-1A cells, S100A4 protein was upregulated after $96 \mathrm{~h}$ of TGF- $\beta 1$ treatment. $\beta$-actin was used as a loading control. (c) TGF- $\beta 1$ treatment did not induce S100A4 in the KLE cells, which we have shown earlier to have methylation of S100A4. ${ }^{6}$

motility, downregulation of epithelial markers such as Ecadherin and cytokeratins, and upregulation of mesenchymal markers such as vimentin and fibronectin. To determine whether TGF- $\beta 1$ could induce EMT of HEC-1A cells in vitro, we then examined the expression of these EMT marker proteins. However, TGF- $\beta 1$ treatment for 5 days did not alter the expression of any of these proteins (data not shown). Nevertheless, TGF- $\beta 1$ did elicit cell morphological changes and enhanced migratory ability and invasiveness of HEC-1A cells in vitro, which has been recognized as cell scattering or incomplete EMT. ${ }^{24}$ The TGF- $\beta$ 1-induced cell scattering phenotype has been reported earlier in normal mammary epithelial NMuMG cells. $^{24-27}$

\section{TGF- $\beta 1$ Induces Smad2 Activation}

Upregulation of S100A4 protein by extended TGF- $\beta 1$ treatment suggested that S100A4 is not one of the early response genes of TGF- $\beta 1$ and that secondary or tertiary signaling pathways are likely needed to activate S100A4 expression. Next, we evaluated the TGF- $\beta 1$ signaling pathways that are potentially associated with the cell scattering phenotype and upregulation of S100A4. Both Smad-dependent and Smadindependent (ie Akt-and Erk-dependent) TGF- $\beta 1$ pathways have been implicated in EMT in various epithelial cell types. ${ }^{28-35}$ First, the Smad-dependent signaling pathway was examined (Figure 6). The phosphorylation of Smad2 was examined at various time points after adding TGF- $\beta 1$ to HEC-1A cells. TGF- $\beta 1$ induced phosphorylation of Smad2 (pSmad2) at all the time points examined, and the level of Smad2 phosphorylation remained elevated for the duration of the experiment without affecting total Smad2 expression. In contrast, pSmad2 was not present in cells treated with vehicle control. Activation of Smad-independent pathways (phospho-Akt and phosphor-Erk1/2), however, was not observed after TGF- $\beta 1$ treatment (data not shown). This suggested that Smad-independent TGF- $\beta$ signaling was not significantly involved in mediating TGF- $\beta 1$ effects on HEC$1 \mathrm{~A}$ cells. Taken together, these data indicate sustained phosphorylation of Smad2 is associated with TGF- $\beta 1$-enhanced cell migration and invasion and the upregulation of S100A4 in HEC-1A cells.

\section{DISCUSSION}

Increased levels of TGF- $\beta 1$ are observed in many human tumors, including endometrial cancer, and are associated with poor clinical outcome. ${ }^{36-42}$ TGF- $\beta 1$ is also an important stimulator of fibrosis in kidney transplant rejection and liver cirrhosis; in these settings, TGF- $\beta 1$ is known to induce S100A4. ${ }^{1-3}$ As TGF- $\beta 1$ enhanced cell motility and invasion in endometrial cancer cells, we tested the effect of TGF- $\beta 1$ on S100A4 expression. We found that S100A4 was upregulated after prolonged TGF- $\beta 1$ treatment. Moreover, S100A4 was required for the increased cell motility and invasion of HEC$1 \mathrm{~A}$ cells by TGF- $\beta 1$, because in HEC- $1 \mathrm{~A}$ cells transfected with S100A4 siRNA, the effects of TGF- $\beta 1$ on the basal migration and invasion rates were significantly reduced. We propose that in invasive endometrial cancers, S100A4 is a significant downstream effector of the TGF- $\beta 1$ signaling pathway through which TGF- $\beta 1$ exerts its pro-migratory and proinvasive effects on endometrial cancer cells. Therefore, wellestablished molecular mediators of fibrosis (TGF- $\beta$ and S100A4) are also important in mediating cancer cell migration and invasion.

One of the mechanisms for transcriptional regulation by DNA methylation involves the binding of methylated DNAbinding proteins such as $\mathrm{MeCP} 2$ to methylated regions. $\mathrm{MeCP} 2$ then recruits transcription repressor complexes containing histone deacetylases to the methylated gene precipitating an inactive chromatin structure, blocking the 
a

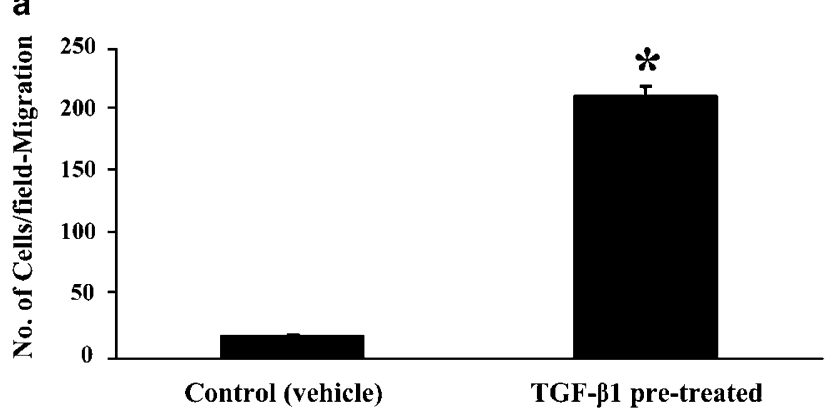

C

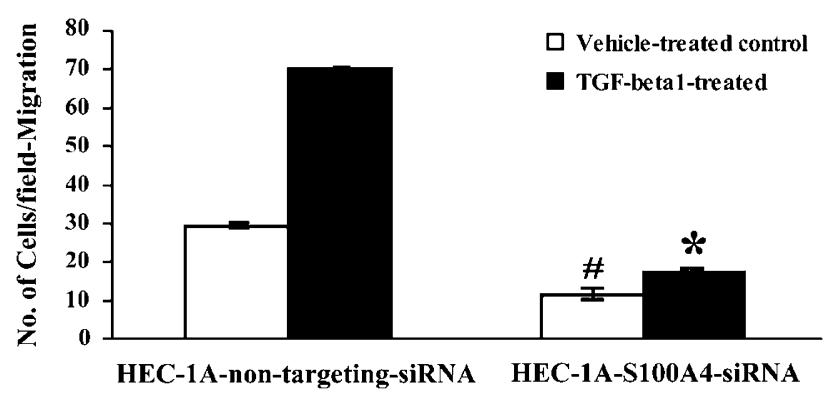

b

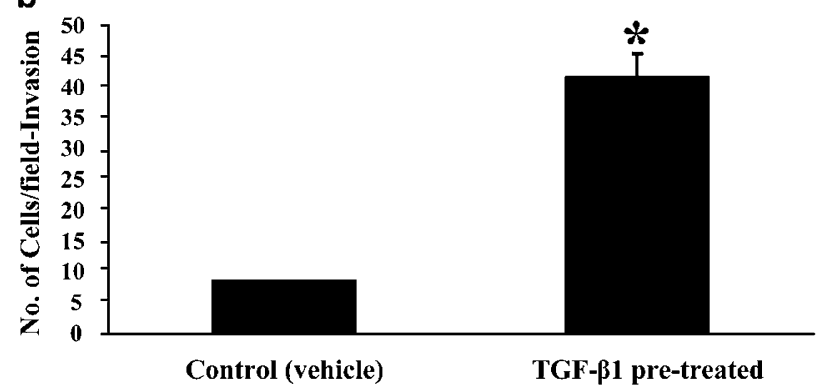

d

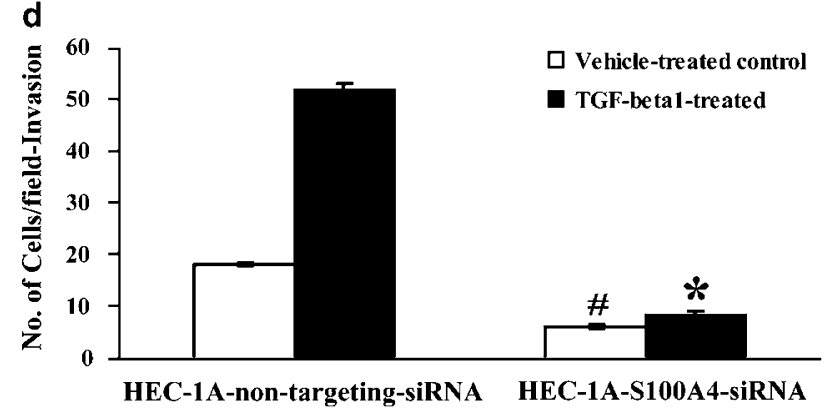

Figure 5 Chronic TGF- $\beta 1$ treatment stimulates endometrial cancer cell migration and invasion. (a and $\mathbf{b}) \mathrm{HEC}-1 \mathrm{~A}$ cells were pretreated with $2.5 \mathrm{ng} / \mathrm{ml}$ of human TGF- $\beta 1$ or an equal volume of TGF- $\beta 1$ vehicle $(4 \mathrm{mM} \mathrm{HCl}$ with $1 \mathrm{mg} / \mathrm{ml}$ bovine serum albumin) for 5 days. The cells were collected by brief treatment with trypsin-EDTA and equal numbers of treated or untreated cells were subjected to migration (a) or invasion (b) assays. Quantification was performed by counting the stained cells using light microscopy. The assays were performed in triplicate, and means were used in statistical analysis. ( $\left.{ }^{\star} P<0.05\right)$. (c and $\mathbf{d}$ ) Knockdown of S100A4 inhibits TGF- $\beta 1$ stimulated endometrial cancer cell migration and invasion. At $36 \mathrm{~h}$ post transfection of non-targeting siRNA or S100A4 siRNA, cells were pretreated with TGF- $\beta 1$ or an equal volume of TGF- $\beta 1$ vehicle for 5 days. Migration (c) and invasion (d) assays were performed as described above. $\left({ }^{*} P<0.05\right.$, TGF- $\beta 1$-treated HEC-1A-S100A4-siRNA vs TGF- $\beta 1$-treated HEC-1A-non-targeting-siRNA control; ${ }^{\#} P<0.05$, vehicle-treated HEC-1A-S100A4siRNA vs vehicle-treated HEC-1A-non-targeting-siRNA control).

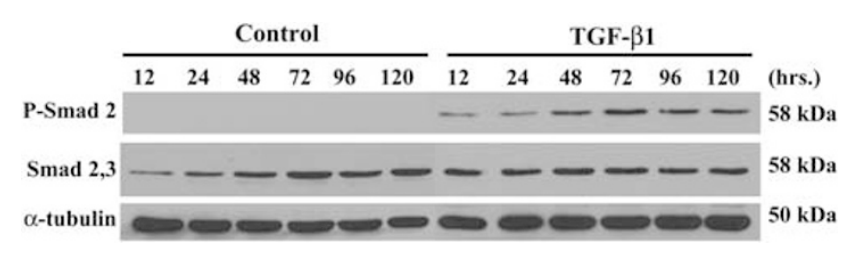

Figure 6 TGF- $\beta 1$ induces phosphorylated Smad2 in HEC-1A cells. HEC-1A cells were treated with TGF- $\beta 1(2.5 \mathrm{ng} / \mathrm{ml})$ or vehicle $(4 \mathrm{mM} \mathrm{HCl}$ with $1 \mathrm{mg}$ / $\mathrm{ml}$ bovine serum albumin) in the absence of serum for the indicated time periods. Western blot revealed the presence of phosphorylated Smad 2 after TGF- $\beta 1$ stimulation, whereas the level of total Smad2/3 was similar between vehicle control and TGF- $\beta 1$-treated HEC-1A cells. No significant differences in total AKT, pAKT, total Erk1,2, and pERK1,2 were observed in TGF- $\beta 1$ treated cells (data not shown).

association of transcription activators and leading to the silencing of gene expression. ${ }^{43-45}$ This might explain the differential effects of TGF- $\beta 1$ on HEC-1A and KLE endometrial cancer cells. We have also shown earlier that the expression of HOXA10 in endometrial carcinoma is regulated by methylation. ${ }^{46}$ Specifically, HOXA10 is overexpressed in low-grade (grade 1) endometrioid carcinomas, but its expression is low in the more clinically aggressive grade 3 endometrioid carcinoma and UPSC. This differential expression pattern is regulated by methylation of the HOXA10 gene. Endometrial cancer cells with manipulated HOXA10 expression have altered in vitro invasion characteristics. In aggregate, these results suggest that epigenetic modifications, such as gene methylation, can play a potentially important role in regulating endometrial cancer invasion.

Previously, S100A4 gene suppression by siRNA led to reduced cell proliferation in a prostate cancer cell line. ${ }^{47}$ However, S100A4 knockdown did not affect endometrial cancer cell proliferation in vitro in this study. Our results are actually quite consistent with previous published findings that transgenic mice overexpressing S100A4 in the mammary epithelium are phenotypically indistinguishable from wildtype mice, demonstrating that S100A4 itself is not tumorigenic. ${ }^{48}$ It is likely that tissue-specific factors dictate whether S100A4 has an effect on cell proliferation. Additionally, invasion is a complex process that involves several different steps of cell migration and proliferation. For endometrial cancer, cell migration and proliferation might represent independent processes that are regulated by different signal transduction pathways. Experimental evidence has shown the lower proliferation rate of migratory cells in comparison with the tumor core, which indicates an inverse correlation between mobility and cell proliferation. ${ }^{49-51}$ Thus, in certain systems, proliferation and migration of tumor cells may be mutually exclusive phenotypes. 
The exact mechanism by which S100A4 stimulates invasion is not understood. S100A4, which is primarily a cytoplasmic protein, could facilitate cancer cell movement by physical interaction with various effectors. ${ }^{52}$ S100A4 protein can bind to cytoskeletal proteins such as actin, ${ }^{53}$ tropomyo$\sin ,{ }^{54}$ and myosin-II. ${ }^{55-57}$ The interaction of myosin-IIA and S100A4 provides a direct link between the actomyosin cytoskeleton and the modulation of cellular motility by S100A4. Localization studies show that during chemotaxis, both S100A4 and myosin-IIA localize primarily to the leading edge of forward cell protrusions. ${ }^{58}$

Additionally, it has been proposed that S100A4 promotes cell invasion by remodeling of the extracellular matrix. ${ }^{52}$ Dysregulation of metalloproteinases is essential for the remodeling of extracellular matrix proteins and for tumor cell migration and invasion. Metastatic osteosarcoma cell lines with downregulated S100A4 have a reduction in the mRNA levels of MMP2, membrane-type 1-MMP, and of the endogenous tissue inhibitor TIMP-1 and a marked reduction in migration through Matrigel-coated filters. ${ }^{59}$ Furthermore, in a human prostate cancer cell line, S100A4 suppression significantly reduced the expression and proteolytic activity of MMP-9. Prostate cancer cells overexpressing the S100A4 gene also significantly expressed MMP-9 and TIMP-1 genes with increased proteolytic activity of MMP- $9 .{ }^{47}$

Regardless of the mechanism of action, it is clear from our present results that high expression of S100A4 is associated with clinical and pathological features linked to poor prognosis. Importantly, we have also demonstrated here by mechanistic studies that S100A4 is an important effector of endometrial cancer cell invasion. From the clinical perspective, there are currently no drugs that specifically target S100A4. However, there are drugs in development for fibrotic diseases that target TGF- $\beta$ receptors; ${ }^{60}$ such drugs may potentially be useful for treatment of advanced endometrial cancer. Furthermore, we have demonstrated here that measuring tumor S100A4 expression has prognostic value. Endometrial cancer patients with high tumor levels of S100A4 may therefore benefit from postoperative adjuvant chemotherapy.

\section{ACKNOWLEDGEMENT}

This work was supported by NIH 1P50CA098258-01 (SPORE in Uterine Cancer) and Schissler Foundation Graduate Student Fellowship in Cancer Research.

1. Robertson $\mathrm{H}$, Ali $\mathrm{S}, \mathrm{McDonnell} \mathrm{BJ}$, et al. Chronic renal allograft dysfunction: the role of T cell-mediated tubular epithelial to mesenchymal cell transition. J Am Soc Nephrol 2004;15:390-397.

2. Okada H, Danoff TM, Kalluri R, et al. Early role of Fsp1 in epithelialmesenchymal transformation. Am J Physiol 1997;273:F563-F574.

3. Rygiel KA, Robertson $\mathrm{H}$, Marshall $\mathrm{HL}$, et al. Epithelial-mesenchymal transition contributes to portal tract fibrogenesis during human chronic liver disease. Lab Invest 2008;88:112-123.

4. Schneider M, Kostin S, Strom CC, et al. S100A4 is upregulated in injured myocardium and promotes growth and survival of cardiac myocytes. Cardiovasc Res 2007;75:40-50.
5. Lawson WE, Polosukhin VV, Zoia O, et al. Characterization of fibroblastspecific protein 1 in pulmonary fibrosis. Am J Respir Crit Care Med 2005;171:899-907.

6. Xie R, Loose DS, Shipley GL, et al. Hypomethylation-induced expression of S100A4 in endometrial carcinoma. Mod Pathol 2007;20:1045-1054.

7. Donato R. Intracellular and extracellular roles of $\mathrm{S} 100$ proteins. Microsc Res Tech 2003;60:540-551.

8. Marenholz I, Heizmann CW, Fritz G. S100 proteins in mouse and man: from evolution to function and pathology (including an update of the nomenclature). Biochem Biophys Res Commun 2004;322: 1111-1122.

9. Micci F, Teixeira MR, Haugom L, et al. Genomic aberrations in carcinomas of the uterine corpus. Genes Chromosomes Cancer 2004;40:229-246.

10. Imazawa M, Hibi K, Fujitake S, et al. S100A2 overexpression is frequently observed in esophageal squamous cell carcinoma. Anticancer Res 2005;25:1247-1250.

11. Weterman MA, Stoopen GM, van Muijen GN, et al. Expression of calcyclin in human melanoma cell lines correlates with metastatic behavior in nude mice. Cancer Res 1992;52:1291-1296.

12. Weterman MA, van Muijen GN, Bloemers HP, et al. Expression of calcyclin in human melanocytic lesions. Cancer Res 1993;53: 6061-6066.

13. Komatsu K, Kobune-Fujiwara $Y$, Andoh A, et al. Increased expression of S100A6 at the invading fronts of the primary lesion and liver metastasis in patients with colorectal adenocarcinoma. $\mathrm{Br} J$ Cancer 2000;83:769-774.

14. Davies BR, O'Donnell M, Durkan GC, et al. Expression of S100A4 protein is associated with metastasis and reduced survival in human bladder cancer. J Pathol 2002;196:292-299.

15. Emberley ED, Niu Y, Njue C, et al. Psoriasin (S100A7) expression is associated with poor outcome in estrogen receptor-negative invasive breast cancer. Clin Cancer Res 2003;9:2627-2631.

16. Stulik J, Osterreicher J, Koupilova K, et al. The analysis of S100A9 and S100A8 expression in matched sets of macroscopically normal colon mucosa and colorectal carcinoma: the S100A9 and S100A8 positive cells underlie and invade tumor mass. Electrophoresis 1999;20: 1047-1054.

17. Nishiu M, Yanagawa R, Nakatsuka $S$, et al. Microarray analysis of gene-expression profiles in diffuse large B-cell lymphoma: identification of genes related to disease progression. Jpn J Cancer Res 2002;93:894-901.

18. Mori M, Shimada H, Gunji Y, et al. S100A11 gene identified by in-house cDNA microarray as an accurate predictor of lymph node metastases of gastric cancer. Oncol Rep 2004;11:1287-1293.

19. FIGO IFoGaO. Announcements. Gynecol Oncol 1989;35:125-127.

20. Callaerts-Vegh Z, Evans KL, Shipley GL, et al. Effects of different beta adrenoceptor ligands in mice with permanent occlusion of the left anterior descending coronary artery. $\mathrm{Br} \mathrm{J}$ Pharmacol 2003;138:1505-1516.

21. Albini A, Iwamoto $\mathrm{Y}$, Kleinman $\mathrm{HK}$, et al. A rapid in vitro assay for quantitating the invasive potential of tumor cells. Cancer Res 1987;47:3239-3245.

22. Albini A. Tumor and endothelial cell invasion of basement membranes. The matrigel chemoinvasion assay as a tool for dissecting molecular mechanisms. Pathol Oncol Res 1998;4:230-241.

23. Galliher AJ, Neil JR, Schiemann WP. Role of transforming growth factor-beta in cancer progression. Future Oncol 2006;2:743-763.

24. Grunert $S$, Jechlinger $M$, Beug $H$. Diverse cellular and molecular mechanisms contribute to epithelial plasticity and metastasis. Nat Rev Mol Cell Biol 2003;4:657-665.

25. Miettinen PJ, Ebner R, Lopez AR, et al. TGF-beta induced transdifferentiation of mammary epithelial cells to mesenchymal cells: involvement of type I receptors. J Cell Biol 1994;127: 2021-2036.

26. Piek E, Moustakas A, Kurisaki A, et al. TGF-(beta) type I receptor/ALK-5 and Smad proteins mediate epithelial to mesenchymal transdifferentiation in NMuMG breast epithelial cells. J Cell Sci 1999;112(Pt 24):4557-4568.

27. Bakin AV, Tomlinson AK, Bhowmick NA, et al. Phosphatidylinositol 3-kinase function is required for transforming growth factor betamediated epithelial to mesenchymal transition and cell migration. J Biol Chem 2000;275:36803-36810. 
28. Xie L, Law BK, Aakre ME, et al. Transforming growth factor beta-regulated gene expression in a mouse mammary gland epithelia cell line. Breast Cancer Res 2003;5:R187-R198.

29. Kasai H, Allen JT, Mason RM, et al. TGF-beta1 induces human alveolar epithelial to mesenchymal cell transition (EMT). Respir Res 2005;6:56.

30. Flanders KC. Smad3 as a mediator of the fibrotic response. Int J Exp Pathol 2004;85:47-64.

31. Xie L, Law BK, Chytil AM, et al. Activation of the Erk pathway is required for TGF-beta1-induced EMT in vitro. Neoplasia 2004;6:603-610.

32. Moustakas A, Heldin CH. Signaling networks guiding epithelialmesenchymal transitions during embryogenesis and cancer progression. Cancer Sci 2007;98:1512-1520.

33. Zavadil J, Bottinger EP. TGF-beta and epithelial-to-mesenchymal transitions. Oncogene 2005;24:5764-5774.

34. Peinado H, Olmeda D, Cano A. Snail, Zeb and bHLH factors in tumour progression: an alliance against the epithelial phenotype. Nat Rev Cancer 2007;7:415-428.

35. Guarino M. Epithelial-mesenchymal transition and tumour invasion. Int J Biochem Cell Biol 2007;39:2153-2160.

36. Yabushita $H$, Narumiya $H$, Hiratake $K$, et al. The association of transforming growth factor-beta 1 with myometrial invasion of endometrial carcinomas through effects on matrix metalloproteinase. J Obstet Gynaecol Res 2000;26:163-170.

37. Krieg P, Schnapke R, Furstenberger G, et al. TGF-beta 1 and skin carcinogenesis: antiproliferative effect in vitro and TGF-beta 1 mRNA expression during epidermal hyperproliferation and multistage tumorigenesis. Mol Carcinog 1991;4:129-137.

38. Maehara $Y$, Kakeji $Y$, Kabashima A, et al. Role of transforming growth factor-beta 1 in invasion and metastasis in gastric carcinoma. J Clin Oncol 1999;17:607-614

39. Gomella LG, Sargent ER, Wade TP, et al. Expression of transforming growth factor alpha in normal human adult kidney and enhanced expression of transforming growth factors alpha and beta 1 in renal cell carcinoma. Cancer Res 1989;49:6972-6975.

40. Gorsch SM, Memoli VA, Stukel TA, et al. Immunohistochemical staining for transforming growth factor beta 1 associates with disease progression in human breast cancer. Cancer Res 1992;52:6949-6952.

41. Walker RA, Dearing SJ. Transforming growth factor beta 1 in ductal carcinoma in situ and invasive carcinomas of the breast. Eur J Cancer 1992;28:641-644.

42. Dalal BI, Keown PA, Greenberg AH. Immunocytochemical localization of secreted transforming growth factor-beta 1 to the advancing edges of primary tumors and to lymph node metastases of human mammary carcinoma. Am J Pathol 1993;143:381-389.

43. Jones PL, Veenstra GJ, Wade PA, et al. Methylated DNA and MeCP2 recruit histone deacetylase to repress transcription. Nat Genet 1998;19:187-191.

44. Nan $\mathrm{X}, \mathrm{Ng} \mathrm{HH}$, Johnson $\mathrm{CA}$, et al. Transcriptional repression by the methyl-CpG-binding protein MeCP2 involves a histone deacetylase complex. Nature 1998;393:386-389.
45. Fuks $F$, Hurd PJ, Wolf $D$, et al. The methyl-CpG-binding protein MeCP2 links DNA methylation to histone methylation. J Biol Chem 2003;278:4035-4040.

46. Yoshida H, Broaddus R, Cheng W, et al. Deregulation of the HOXA10 homeobox gene in endometrial carcinoma: role in epithelialmesenchymal transition. Cancer Res 2006;66:889-897.

47. Saleem M, Kweon MH, Johnson JJ, et al. S100A4 accelerates tumorigenesis and invasion of human prostate cancer through the transcriptional regulation of matrix metalloproteinase 9. Proc Natl Acad Sci USA 2006;103:14825-14830.

48. Ambartsumian NS, Grigorian MS, Larsen IF, et al. Metastasis of mammary carcinomas in GRS/A hybrid mice transgenic for the mts 1 gene. Oncogene 1996;13:1621-1630.

49. Giese $A$, Bjerkvig $R$, Berens $M E$, et al. Cost of migration: invasion of malignant gliomas and implications for treatment. J Clin Oncol 2003;21:1624-1636.

50. Giese A, Loo MA, Tran N, et al. Dichotomy of astrocytoma migration and proliferation. Int J Cancer 1996;67:275-282.

51. Merzak A, McCrea S, Koocheckpour S, et al. Control of human glioma cell growth, migration and invasion in vitro by transforming growth factor beta 1. Br J Cancer 1994;70:199-203.

52. Mazzucchelli L. Protein S100A4: too long overlooked by pathologists? Am J Pathol 2002;160:7-13.

53. Watanabe $\mathrm{Y}$, Usada $\mathrm{N}$, Minami $\mathrm{H}$, et al. Calvasculin, as a factor affecting the microfilament assemblies in rat fibroblasts transfected by src gene. FEBS Lett 1993;324:51-55.

54. Takenaga K, Nakamura Y, Sakiyama S, et al. Binding of pEL98 protein, an S100-related calcium-binding protein, to nonmuscle tropomyosin. J Cell Biol 1994;124:757-768.

55. Kriajevska MV, Cardenas MN, Grigorian MS, et al. Non-muscle myosin heavy chain as a possible target for protein encoded by metastasis-related mts-1 gene. J Biol Chem 1994;269: 19679-19682.

56. Li ZH, Bresnick AR. The S100A4 metastasis factor regulates cellular motility via a direct interaction with myosin-IIA. Cancer Res 2006;66:5173-5180

57. Dulyaninova NG, Malashkevich VN, Almo SC, et al. Regulation of myosin-IIA assembly and Mts1 binding by heavy chain phosphorylation. Biochemistry 2005;44:6867-6876.

58. Tarabykina S, Griffiths TR, Tulchinsky E, et al. Metastasis-associated protein S100A4: spotlight on its role in cell migration. Curr Cancer Drug Targets 2007;7:217-228.

59. Bjornland K, Winberg JO, Odegaard OT, et al. S100A4 involvement in metastasis: deregulation of matrix metalloproteinases and tissue inhibitors of matrix metalloproteinases in osteosarcoma cells transfected with an anti-S100A4 ribozyme. Cancer Res 1999;59: 4702-4708

60. Yingling JM, Blanchard KL, Sawyer JS. Development of TGF-beta signaling inhibitors for cancer therapy. Nat Rev Drug Discov 2004;3:1011-1022. 